\title{
NEOCONSERVADORISMO MORAL NA AGENDA POLITICA DAS NOVAS DIREITAS
}

MORAL NEOCONSERVATISM IN POLITICAL AGENDA OF NEW RIGHTS

\section{Adalberto Ferdnando Inocêncio}

Doutor em Ensino de Ciências pelo Programa de Pós-graduação em Ensino de Ciências e Educação Matemática pela Universidade Estadual de Londrina (PECEM/UEL). Professor temporário no Departamento de Pedagogia do campus regional de Cianorte da Universidade Estadual de Maringá (UEM).

\section{Camila Carolina Hildebrand Galetti}

Mestra e doutoranda em Sociologia pelo Programa de Pós-graduação em Sociologia da Universidade de Brasília (UnB). Pesquisadora do Projeto Mulheres Eleitas do Laboratório de Eleições, Partidos e Política Comparada da Universidade Federal do Rio de Janeiro (LAPPCOM/UFRJ). 


\section{RESUMO}

O artigo analisa as táticas políticas mobilizadas por conservadorismos morais, que estão em vigência no governo de Jair Bolsonaro, bem como de que modo elas contribuem para o enfraquecimento da democracia brasileira. Com isso, na primeira seção, a discussão se concentra em conceitualizar o conservadorismo moral e clássico para que seja possível compreender as novas nuances impulsionadas pelo bolsonarismo. Na segunda seção, apresenta-se e discute-se o bolsonarismo como fenômeno político, e de que modo este canaliza o conservadorismo moral da população para interesses próprios. A terceira e última seção é dedicada a analisar de que maneira o conservadorismo moral de viés bolsonarista estampa algumas manchetes, reforçando uma estética reacionária, a qual exprime retrocessos.

Palavras-chaves: conservadorismo; bolsonarismo; democracia; novas direitas.

\section{ABSTRACT}

The article analyzes the political tactics mobilized by moral conservatism, which are in effect during the Jair Bolsonaro government, as well as how these contribute to the weakening of Brazilian democracy. Thus, in the first section, the discussion focuses on conceptualizing the moral and classical conservatism, so that it is possible to understand the new nuances driven by pocketnarism. The second section introduces and discusses bolsonarismo as a political phenomenon, and how it channels the population's moral conservatism towards its own interests. The third and last section is dedicated to analyzing how moral conservatism with a bolsonarismo bias prints some headlines, reinforcing a reactionary aesthetic, which expresses setbacks.

Keywords: conservatism; bolsonarism; democracy; new rights. 


\section{Introdução}

O objetivo geral deste artigo foi o de cartografar táticas políticas acionadas por conservadorismos morais que caracterizam o regime bolsonarista em vigência. Desse modo, foi necessário investigar elementos anteriores ao período que institucionaliza o mandato do atual chefe do Executivo, uma vez que a "capilarização" desse fenômeno político se intensifica na sociedade brasileira durante a campanha das últimas eleições (FREIXO; PINHEIRO-MACHADO, 2OI9).

Para além disso, está subjacente a tal objetivo o esforço de analisar o quanto o conservadorismo moral afeta e enfraquece a democracia, como afirma Demirovic (2018), de modo que, em muitos países, se observa um aumento do nacionalismo e do autoritarismo, culminando numa ameaça ao Estado de Direito e à democracia. Nas palavras do autor:

Significativamente, esses processos às vezes de longo alcance são executados e representados pelo populismo autoritário de direita e seus representantes. O populismo autoritário geralmente define a agenda política e propaga objetivos políticos nacional-conservadores, racistasetnocêntricos e estatistas-autoritários. ${ }^{1}$ (DEMIROVIC, 20I8, p. II7, tradução nossa).

Trabalha-se com a hipótese de que o bolsonarismo aciona táticas políticas mais amplas dentro de um espectro do neoconservadorismo atual e, para além disso, os setores da mídia hegemônica se utilizam das mesmas táticas, mobilizando afetos dos indivíduos e potencializando o pânico moral, que passa a ser canalizado aos modos de vida não enquadrados ao ideário neoconservador. Parte desse fenômeno se explica por conta de a dinâmica incitada nas redes operarem produzindo controvérsias.

Nas seções analíticas, foram selecionadas manchetes jornalísticas que acionam em seu texto um conteúdo atinente ao neoconservadorismo moral. Argumenta-se que tais conteúdos são resultado da ascensão do bolsonarismo no contexto brasileiro.

Estruturalmente, a primeira seção deste artigo mostra algumas diferenças entre o conservadorismo do tipo clássico e o neoconservadorismo moral, com ênfase na relação íntima que o segundo estabelece com as agendas neoliberais. Em seguida, apresenta-se e discute-se o bolsonarismo como fenômeno político, e de que modo este canaliza o neoconservadorismo moral da população para interesses próprios, tendo como finalidade o fortalecimento de um governo autoritário e excludente no que tange às pautas

\footnotetext{
1 "Significativamente, estos procesos a veces de gran alcance son ejecutados y representados por un populismo de derechas y autoritario y por sus representantes. El populismo autoritario a menudo determina la agenda política y propaga objetivos políticos nacional-conservadores, racistas-etnocéntricos y estatistas-autoritario" (DEMIROVIC, 2018, p. 117).
} 
relacionadas às diversidades sociais e sexuais. Na terceira e última seção, analisa-se de que modo o conservadorismo moral de viés bolsonarista estampa algumas manchetes, reforçando uma estética reacionária que exprime retrocessos.

\section{Conservadorismo clássico e moral: entornos conceituais}

O neoconservadorismo atual se distingue de seu sentido clássico tendo como ressalva que ambos não podem ser entendidos como universais, de modo que sofrem influência do contexto marcado pela história do país, da nação e de seu povo.

Em linhas gerais, Scruton (2015) afirma que no sentido clássico o conservadorismo adota uma visão determinista de mundo, uma vez que se apoia na natureza para explicar fenômenos sociais. Desse modo, assume uma postura cética diante das transformações do mundo, isto é, por não acreditar/confiar na capacidade da humanidade em conduzi-las que ele pende à conservação do mundo tal como este se apresenta em dado momento histórico-político (SCRUTON, 2OI5).

Uma grande diferença do conservadorismo clássico comparado ao neoconservadorismo moral, é que o primeiro herda os ideais iluministas, ou seja, está amparado na liberdade, no progresso, na tolerância, na fraternidade, no governo constitucional e na separação entre igreja e estado. Por isso, acredita na lei antes da vontade; e na razão antes do interesse individual (SCRUTON, 2OI5). O neoconservadorismo moral, por sua vez, adere a um sistema de crenças e afetos, em vez da verdade. Além disso, apesar de seus efeitos decorrerem das crenças de um grupo, não abandona os interesses individuais, uma vez que, na atual conjuntura global, se caracteriza pela imbricação com os princípios neoliberais (ALMEIDA, 2OI8; BIROLI; MACHADO; VAGGIONE; 2O20; BROWN, 20I9; DARDOT; LAVAL, 20I6; SAFATLE, 2020).

Contudo, algumas similaridades do conservadorismo atual já anunciavam raízes em suas facetas clássicas. Dessas, destacam-se a defesa da não intervenção estatal nas comunidades civis e das leis orgânicas, o que está subjacente, por sua vez, à descrença em relação à política como mediação entre Estado e cidadãos que habitam um território. $\mathrm{O}$ conservadorismo, em sentido clássico, acredita na sociedade, mas não na política (SCRUTON, 20I5).

Para Dardot e Laval (2016), o recrudescimento dos movimentos neoconservadores, ou mesmo os de caráter neofascista, ${ }^{2}$ tem sua raiz nas transformações subjetivas provocadas pela hegemonia neoliberal. Para os autores, essa base de pensamento fortalece os ideais de meritocracia e individualismo social, ao passo que se localizam diametralmente em

\footnotetext{
${ }^{2}$ Adota-se o prefixo neo por compreender-se que o fascismo do tempo presente exibe outra roupagem, fruto do seu tempo, ainda que resguarde velhos hábitos, mas não é algo completamente diferente dos fascismos de décadas anteriores.
} 
oposição aos princípios de redistribuição e solidariedade. Para eles, o neoliberalismo ainda permite com que haja um enfraquecimento dos movimentos sociais, em oposição a um fortalecimento de narrativas que reduzem tais movimentos como inimigos da moralidade.

O componente moral, somado ao capitalismo global em alguns países, é um dos componentes que explica o motivo de alguns grupos se manterem no poder apesar de inúmeras denúncias por corrupção: "Corrupção, para o político fascista, consiste na corrupção da pureza, e não da lei" (STANLEY, 2020, p. 39).

Economia e moral não são elementos paradoxais e opostos, mas componentes que se coadunam desde os pensadores clássicos, podendo ser encontrados nos escritos de John Locke, Adam Smith e David Hume. Para Mill (1973), que atualiza esses pensadores numa nova base de pensamento, a economia política, além de uma ciência que trata da produção e distribuição de riqueza, também podia ser associada "a leis morais ou psicológicas da produção e distribuição da riqueza" (p. 303).

Nessa perspectiva, sustenta-se o argumento de que regulações econômicas não podem ser entendidas como quadros neutros ou estanques, ou como meros estudos que visam simplesmente responder às oscilações de mercado. Em sua dobra financeirizada, o neoliberalismo se alimenta das pautas morais: "Nenhum modo de pensamento se torna dominante sem propor um aparato conceitual que mobilize nossas sensações e nossos instintos, nossos valores e nossos desejos" [...] (HARVEY, 2OI3, p. I5).

$\mathrm{Na}$ análise de Safatle (2020), até mesmo as políticas de austeridade não podem ser entendidas simplesmente como um termo técnico da teoria econômica, mas um termo proveniente da filosofia moral, uma vez que na prática dessas políticas existe a justificação de ações econômicas em detrimento do "sacrifício" de certos grupos de indivíduos com base em um julgamento moral. Nesses desdobramentos, a crença dos indivíduos passa a se inserir como componente chave nas articulações políticas, sendo que se torna cada vez mais evidente de que modo "lutas políticas tendem a não ser mais apenas descritas a partir de termos eminentemente políticos, como justiça, equidade, exploração, espoliação, mas através de termos emocionais, como ódio, frustração, medo, ressentimento [...]" (SAFATLE, 2O2O, p. 2I-22).

Com base nos efeitos dessa "economia moral", Brown (2019) defende que uma das facetas dessa racionalidade política se expressa nas tentativas de forte regulação da moralidade sexual. Essa racionalidade promove um tipo de cultura política, mas também de subjetivação, que prioriza a mobilização do direito de proteger e garantir uma moral sexual baseada na defesa da família tradicional e nuclear (heterossexual e monogâmica), a qual estaria legitimada por seu potencial reprodutivo, argumento também endossado por Biroli, Machado e Vaggione (2020). 
Com base nas teorizações apresentadas, adotou-se nesta investigação a premissa de que "[...] o conservadorismo é posicional, e a ideologia e o movimento político conservadores se desenvolvem em resposta ou resistência a situações históricas de mudanças na estrutura social e política" (BIROLI; MACHADO; VAGGIONE, 2020, p. 24). Em outros termos, ideologia e iniciativas conservadoras tendem a aparecer quando segmentos sociais minoritários desafiam a ordem estabelecida a ponto de ameaçar os fundamentos que sustentam as instituições em questão.

Como se considera que o bolsonarismo representa, na atual conjuntura, uma dessas situações históricas de mudança na estrutura social e política na realidade brasileira, capaz de canalizar e reorientar posições neoconservadoras, a próxima seção está organizada à apresentação e discussão desse fenômeno político.

\section{Bolsonarismo político: uma condição de existência para a moral neoconservadora}

A "fixação" pelas pautas morais não é exclusividade das novas direitas. Bobbio (20II) já caracterizava a direita clássica pelos ideais que envolvem o individualismo; a supremacia da propriedade privada e da livre iniciativa; a primazia do sagrado; a valorização da ordem e da tradição; o militarismo e a defesa da segurança nacional; o elogio da nobreza e do heroísmo; e, no que mais cabe ressaltar nesta investigação, a intolerância à diversidade étnica, cultural e sexual, para ficar nesses exemplos. O que a nova direita exerce é uma intensificação desse processo, utilizando-o como modo de governamento e principal aposta de fixação de seu ideário.

Freixo e Pinheiro-Machado (2019) conceituam:

[...] o bolsonarismo [...] como um fenômeno político que transcende a própria figura de Jair Bolsonaro, [...] se caracteriza por uma visão de mundo ultraconservadora, que prega o retorno aos "valores tradicionais" e assume uma retórica nacionalista e "patriótica", sendo profundamente crítica a tudo aquilo que esteja minimamente identificado com a esquerda e o progressismo. Tal visão ganhou bastante força nesta última década em várias partes do mundo, se alimentando da crise da representação e da descrença generalizada na política e nos partidos tradicionais. No Brasil, ela iria encontrar sua personificação no ex-capitão e em seu estilo de fazer política, calcado na lógica do "contra tudo o que está aí", apesar de ele mesmo ser parte do establishment político desde I988 [...] (FREIXO; PINHEIRO-MACHADO, 2OI9, p. I9).

Tal definição sugere que para que se compreenda o fenômeno do bolsonarismo atual é preciso fazer uma digressão ao que alguns autores designaram de agenda antipetista, e de como afetos foram mobilizados para consolidar o ódio ao Partido dos Trabalhadores (PT). 
A agenda midiática antipetista ganha contornos acentuados a partir de 20I3, quando a figura da então presidenta Dilma Rousseff foi alvo das mais variadas críticas misóginas. Para além das direcionadas à sua hipotética incompetência de governar, interessam, nesta investigação, os posicionamentos que envolveram "questões morais", como o fato de que ela seria pró-aborto, para iniciar com esse exemplo (GALLEGO, 20I9). No contexto das eleições daquele ano, tais pautas foram insistentemente mobilizadas midiaticamente pela oposição.

Como apontam os resultados da pesquisa realizada por Carniel, Ruggi e Ruggi (20I8), analisando alguns memes ${ }^{3}$ direcionados a Dilma, cerca de $26 \%$ do total denotavam sua imbecialização, o que agravaria em uma desautorização de suas capacidades cognitivas. Alguns traçavam comparação do cérebro da ex-presidenta ao sistema excretor, insinuando que ela não seria aprovada em um teste psicológico por ser hipersensível, emotiva e descontrolada, como sugeriam as diversas capas de revistas das mídias hegemônicas no período citado (GALETTI, MELO, 2020).

Desse modo, sustenta-se que o golpe de 20I6, que culminou no impeachment da então presidenta Dilma Rousseff, significou, também, "[...] um marco importante de uma ruptura institucional engendrada por antigas elites econômicas, políticas e midiáticas do País" (FREIXO; PINHEIRO-MACHADO, 20I9, p. I9). Controvérsias como as descritas encontram-se potencializadas na sociedade brasileira do pós-golpe, uma vez que são pautas da aliança conjuntural entre atores católicos e evangélicos tradicionalistas, que se caracteriza pelo forte crescimento de grupos neopentecostais em diversos países do continente americano. Essa aliança baseia-se na rejeição comum ao aborto e à homossexualidade, embora haja ênfases diferentes nesse sentido, de modo que o neoconservadorismo católico é inflexível quanto à questão do aborto, uma vez que não há, dessa perspectiva moral, possibilidade de exceções à sua criminalização (BIROLI; MACHADO; VAGGIONE, 2020).

$\mathrm{Na}$ conjuntura pós-eleições presidenciais de 20I4, o protagonismo com que o bloco pentecostal hegemônico ("evangélicos"/"bancada evangélica") se moveu entre os setores Legislativo e Executivo, e mobilizou a sociedade civil e os meios de comunicação evangélicos do país a seu favor contribuiu, de maneira notável, no desfecho do processo de impeachment da então presidenta Dilma Rousseff. Na análise de Burity (2018), a agenda política desses grupos é, preponderantemente, conservadora e moral, tendo culminado em uma das mais reacionárias formações políticas da história republicana do país.

Em 2015, quando já se visibiliza um apoio explícito ao impeachment de Dilma, ao passo que se constrói uma retórica de apoio à figura do então juiz Sérgio Moro, que teria a missão de "limpar" o Brasil da corrupção. Nesse contexto, Gallego (2019) afirma que o

\footnotetext{
${ }^{3}$ Termo utilizado no ciberespaço para se referir ao fenômeno de "viralização" de uma informação, ou seja, qualquer vídeo, imagem, frase, ideia, música que se espalhe entre vários usuários rapidamente, alcançando popularidade.
} 
direcionamento de ataques moralistas não se resumia às figuras do Executivo. Ao longo dos anos 2014-2017, a narrativa dos grupos investigados pode ser resumida em frases como "direitos humanos para humanos direitos". Assim, a narrativa antipetista esteve entremeada com a proposição política de uma agenda galgada nos direitos humanos o que, por sua vez, fora associada à proteção de bandidos ou criminosos, desprotegendo a figura do "cidadão de bem", o que é considerado pela autora como uma inversão moral, mas num sentido moralista do termo (GALLEGO, 2019).

Outra rede importante na veiculação das mensagens antipetistas foi encampada por alguns setores do movimento neopentecostal, que moveu uma de suas principais estratégias de mobilização de rua para implementar sua agenda moral, a Marcha para Jesus. Em junho de 2015, no auge da campanha pelo impeachment da então presidenta, acontecia na cidade de São Paulo a 23- Marcha para Jesus, em que 340 mil participantes (segundo a Polícia Militar) pediam uma "faxina ética". Na perspectiva de Jasper (2016), tal acontecimento pode ser interpretado como uma narrativa neopentecostal da guerra contra o mal, conduzida por choque ou pânico morais.

\footnotetext{
Pânicos morais são fenômenos coletivos que surgem como evidência de uma preocupação social profunda sobre temas como moralidade sexual, consumo de drogas ou outras formas de comportamentos considerados ameaçadores para a sociedade em determinado momento. Esses pânicos surgem em contextos históricos específicos e se espalham com o apoio da mídia, de órgãos governamentais ou grupos organizados a partir do que consideram ser um perigo contra o qual devem lutar. Logo um caso isolado é alçado à condição de "ameaça" e se torna de interesse público, pauta reportagens, livros, relatórios governamentais e ações efetivas para erradicá-la. (MISKOLCI, 2OI3, p. 23I-232).
}

Cabe destacar que essa estratégia não é novidade na arena política brasileira, bem como a participação política dos evangélicos como um todo, que se potencializou durante a Assembleia Nacional Constituinte(ANC), realizada entre I987 e I988. A ANC contou com um grande contingente de deputadas e deputados de confissão cristã evangélica, reconhecida/os como uma "grande novidade" política. A maioria se amparava na ideia de que a Bíblia é a constituição espiritual do homem e, por isso, devia ter sua presença destacada na mesa da ANC (GALETTI, 2020).

Com tais dados, pretende-se visibilizar a relação das mídias - corporativas e digitais - na veiculação e no uso tático de acontecimentos lidos como ameaças, sob a lógica moralista imanente à projeção do bolsonarismo na última década.

Ao mapear alguns acontecimentos que fazem jus a essa interface, Freixo e PinheiroMachado (2019) sinalizam para o atentado sofrido pelo capitão reformado durante a 
campanha, de modo que, poucas semanas depois, recebe apoio do bispo Edir Macedo, que acompanha toda a máquina religiosa e midiática da Igreja Universal, somada a outros líderes neopentecostais, como o pastor Silas Malafaia e o bispo Rodovalho, da Igreja Sara Nossa Terra.

Ainda de acordo com os autores, um dos motivos que contribuiu para o candidato despontar em primeiro lugar foi a disseminação de fake news por meio das novas mídias digitais, notadamente os grupos da rede social WhatsApp. A rejeição aos veículos midiáticos oficiais, expressa na ausência aos debates televisivos, caracterizou a campanha do candidato por uma agenda de ordem moral.

Nessa linha, Biroli (20I7) desenvolve a noção de moralismo compensatório para se referir ao preenchimento moral de esferas que se tornam desassistidas pelo Estado. Num país que aderiu ao neoconservadorismo, tal preenchimento tem como efeito o fortalecimento da instituição família nuclear ou tradicional como fundamento ou pedra angular de agendas específicas. Essas agendas combinam políticas de "austeridade", que restringem o papel do Estado em áreas consideradas fundamentais, tendo como consequência uma limitação do alcance que certas políticas sociais tinham até então, bem como o incentivo a recursos privados, o que, na prática, tem o efeito de exigir mais das famílias (BIROLI; QUINTELA, 2O2I).

Em consonância ao supracitado, Brown (2019) argumenta que a família e a religião são os condutores de discursos e percepções da moral pretendida pelos neoconservadores. O núcleo familiar tornou-se uma arma potente na tentativa de destruir quaisquer valores que supostamente rivalizem com os ideais neoconservadores. Nessa lógica, a família funciona como rede de proteção, um reservatório de disciplina e uma estrutura de autoridade, e, por isso, se constrói em oposição aos excessos da democracia e das minorias, o que culmina no fato de que um dos focos do neoconservadorismo é o ataque a posições que façam alusão à justiça social (BROWN, 2019).

É nítido que tais direcionamentos não favorecem a maior parte dos núcleos familiares brasileiros, daí a interpretação de que algum espaço "é preenchido" pelo moralismo compensatório. A lógica é: "apesar de desfavorecidos economicamente, somos assegurados nos valores morais". Em outras palavras, é como se consagrasse uma resposta empreendedora e individual a problemas de gênese estrutural e sistêmica, criados e ensejados por grupos que visam manter hegemonia. Nesse enlace está presente a aliança nítida entre as esferas moral e econômica.

Disso decorre que "Para iludir e mistificar, criam-se inimigos imaginários (os direitos humanos, a democracia representativa, a degradação moral, a depravação sexual, a diversidade, as minorias, Lula, Kirchner, Correa etc.)" (CASARA, 2019, p. 22, grifo nosso) que, 
de acordo com o contexto, podem ser não apenas apresentados como os responsáveis pelos problemas concretos suportados pela população, como também alvos do Poder Judiciário.

Os argumentos desse autor demonstram que os setores midiáticos não operam de modo independente na guinada conservadora da política, de modo que a mídia hegemônica ocupa uma posição indispensável no papel de condenação do alvo escolhido em cada contexto, reiterando uma série de notícias com teor negativo acerca dos indivíduos que busca condenar com a adesão da opinião pública e, por antítese, também trabalhar na construção de um messias, que atua em cada contexto.

Essas considerações teóricas são reafirmadas numa investigação que reuniu diversos grupos bolsonaristas de visibilidade nas redes sociais. Messenberg (2019) reuniu como campos semânticos associados ao conservadorismo moral as seguintes ideias-força: família tradicional, resgate da fé cristã, patriotismo, anticomunismo, combate à criminalidade/aumento de violência e oposição às cotas raciais.

Nas análises desta investigação, a autora percebeu um liame fascista do bolsonarismo, que se caracterizou numa oposição "nós" e "eles", de modo que "eles" assumem caráter flutuante. De acordo com o contexto e com os grupos específicos que adotam a conspiração circulada nas mídias, os supostos inimigos podem ser desde organizações e partidos, a grupos específicos: comunistas, negros, gays, feministas e todos aqueles que não compartilham dos ideais ensejados pelo sistema executivo em vigor. Assim, as emissões discursivas presentes no campo semântico "conservadorismo moral", investigado por ela, envolvem, de maneira extremada, "conteúdos de natureza homofóbica, sexista, racista e xenófoba" (MESSENBERG, 2019, p. 4I).

Os dados da pesquisa de campo referida anteriormente demonstram com nitidez que características suprapartidárias - que envolvem atributos identitários dos indivíduos são acionadas para apartar grupos, tática que está imanente à retórica mais ampla de criação de inimigos comuns. Esses elementos contribuem para o entendimento de que os domínios "público" e "privado", compreendidos separadamente, não são mais suficientes para entender o imaginário da produção de inimigos políticos pelas novas direitas.

O conjunto de análises desses autores se coaduna no sentido de concordar que Bolsonaro não reorganizou o sistema político no sentido clássico, partidário ou de expressão. Seu modo de governar é sui generis, e se caracteriza pela crise como modo de governo somado a reiteradas tentativas de localizar a si mesmo como contra o establishment. E um dos meios pelos quais ele faz críticas a seus opositores é tanto pela desmoralização do próprio sistema, como de todos aqueles que com ele se identificam, o que contribui por caracterizar esses elementos como "velha política".

Para além do já mencionado, essa maneira de fazer política contribui para o enfraquecimento do estado democrático de direito, no sentido de colocar em xeque tanto 
sua efetividade, quanto no que tange às questões morais, ao criar narrativas falsas e atacar avanços como o voto eletrônico. Sobre esse último aspecto, as eleições de 2018 foram marcadas por narrativas que permeiam um suposto golpe via voto eletrônico e a defesa do voto impresso pelo atual presidente Jair Bolsonaro, e diversas candidatas a deputada federal, à época, como Bia Kicis ${ }^{4}$ (PSL-DF) e Carla Zambelli (PSL-SP).

Desse modo, as análises aqui empreendidas alinham Bolsonaro a uma leva de novos políticos que alavancam sua agenda em termos emocionais, capazes de mobilizar setores da população como se estivessem diante de sujeitos que respondem aos afetos que tais figuras da polícia agenciam.

Ao acentuar os contornos das teorizações reunidas até aqui, a próxima seção busca visibilizar alguns dos efeitos que o bolsonarismo, encampado pelo neoconservadorismo moral, visibiliza midiaticamente. Como já anunciado, se os setores midiáticos são peça fundamental no casamento entre neoconservadorismo e neoliberalismo, qualquer tentativa de redemocratização passa, de modo incontornável, por analisar quais táticas são operadas por tais setores.

\section{Bolsonarismo nas mídias: o neoconservadorismo das manchetes}

O primeiro bloco de análises se refere às manchetes referentes a declarações públicas do atual chefe do Executivo circuladas pelas mídias de massa. Tais declarações seriam lidas como mais absurdas se não fossem acionadas por meio da propaganda política, que, em contextos de crise de referências, abrandam o caráter explícito da usurpação da ordem tradicional. Cabe ressaltar que propagandas podem ser condutoras de governos autoritários que se pautam em conservadorismos morais, e isso é possível de ser vislumbrado no decorrer da história, principalmente em regimes de cunho fascista e nazista (STANLEY, 2020).

É imprescindível mencionar que as manchetes selecionadas para análise se integram em uma rede mais ampla de enunciados ${ }^{5}$ emitidos pelo chefe do executivo ao longo dos anos. Evidencia-se, logo de início, que a maioria das reportagens destacadas aqui, bem como as que cotidianamente circulam, demonstram ataques nítidos a grupos minoritários, como mulheres, negros e negras, LGBTQIA+, conforme relatado a seguir.

\footnotetext{
${ }^{4}$ BRASIL PARALELO. Como o PT destrói a DEMOCRACIA que diz proteger. $5 \mathrm{~m} 19 \mathrm{~s} .11$ out. 2018. Disponível em: $<$ https://www.youtube.com/watch?v=1vyyK_c1tyQ>. Acesso em: 01 ago. 2021

${ }^{5}$ Enunciados integrados com o contexto político global que, inclusive, não se restringem à atual conjuntura. Stanley (2020, p. 38) relata um acontecimento no qual um dos chefes de gabinete estadunidense publiciza anotações de um diário do então presidente Richard Nixon, que datam de 1969, as quais aludem, expressamente, a posicionamentos racistas: "Temos de encarar o fato de que todo o problema resume-se aos negros [...]" " "O segredo é divisar um sistema que reconheça isso, embora sem parecer fazê-lo". O que a nova direita faz, nesse sentido, é reatualizar tais enunciados em contraposição a posições liberais democráticas.
} 
Declarações racistas despontam desde o primeiro semestre do mandato do atual presidente. Mais precisamente em junho de 2019, em visita a uma comunidade quilombola localizada na cidade de Eldorado(SP), Bolsonaro chega a se referir a um dos habitantes como

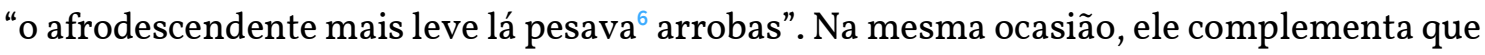
tais habitantes "não fazem nada" (CARVALHO, 20I9, s./p.). A mesma expressão é reutilizada em fevereiro de 2020, desta vez voltada a um apoiador, que declarara, na ocasião: "Bolsonaro, sou negão, votei em você, e, em 2022, vou votar de novo. Você é o melhor presidente do Brasil", disse o apoiador, negro, ao presidente. A resposta do chefe do Executivo foi: "E você está com oito arrobas" (EM EVENTO, 2020, s./p.). O texto da matéria ainda complementa que tal declaração arrancou risadas dos que estavam presentes.

“O papel da propaganda política é ocultar os objetivos claramente problemáticos de políticos ou movimentos políticos, mascarando-os com ideais amplamente aceitos" (STANLEY, 2O2O, p. 37). Nessa perspectiva, o bolsonarismo nada tem de ingênuo, jogando com representações desmoralizadas de figuras identitárias no decorrer dos últimos anos. Suas declarações assentam-se na subjugação desses grupos, já naturalizadas por diversos setores da mídia, na retórica do inimigo comum. Elas funcionam como mote para mascarar, nos termos de Stanley (2020), as inúmeras falhas de gestão do executivo em tentativas de apelo moral à população.

Como defendido anteriormente, o bolsonarismo, como estética, não se resume à figura do chefe do Executivo. Doravante, procurar-se-á demonstrar que o conservadorismo moral ensejado pelo resultado das eleições capilarizou-se em vários circuitos midiáticos, que souberam "surfar" na onda neoconservadora. Tais artifícios valem-se das mesmas retóricas bolsonaristas, isto é, direcionam-se à índole das figuras públicas, em vez de voltadas à qualidade de seu exercício profissional.

Nesse exercício, uma das abordagens da mídia de massa foi o "deslocamento" da figura do ex-ator Mário Frias, nomeado para o cargo de secretário de cultura, em substituição à então atriz Regina Duarte, que deixou a pasta em maio de 2020. Utiliza-se "deslocamento" para se referir a uma tática midiática empregada pela edição de junho do jornal Folha de S. Paulo (Figura I), que, nesse caso, escolhe de maneira não arbitrária uma foto que fez parte do ensaio do referido ator para o extinto site Paparazzo, em 2006. A discursividade em questão diz respeito à tentativa de desmoralizar a escolha do atual presidente. A mesma foto circulou por meio de vários veículos de imprensa na época, bem como por mídias alternativas, como as redes sociais.

A escolha do ator, situado exteriormente aos espaços políticos, é estratégica, mas vai além disso. Ao selecionar, como foto representativa, a silhueta do ator, de bruços, com a

\footnotetext{
${ }^{6}$ Disponível em: <https://www.brasildefato.com.br/2019/06/07/quilombolas-que-foram-alvo-de-bolsonaro-criticamarquivamento-de-processo-de-racismo>. Acesso em: 08 jul. 2021.
} 
região do cóccix à mostra, a sexualidade da figura em questão é imediatamente acionada como interdiscurso. Embora seja de domínio comum que Mário Frias tenha orientação heterossexual, a foto traz em primeiro plano uma posição diametralmente oposta daquilo que a sociedade ocidental falocêntrica estipula como valorativo. Um dos ensaios críticos à manchete em questão a captou da seguinte maneira: "Enxergam um homossexual ${ }^{7}$ na posição passiva. O título 'O novo homem do presidente', usado em matéria da Folha de $S$. Paulo, dá à foto aspecto ainda mais pejorativo" (BENÍCIO, 2020, s./p.).

Figura 1. Chamada do jornal Folha de S. Paulo que faz referência ao novo secretário de cultura do Governo Federal em vigência. ${ }^{7}$

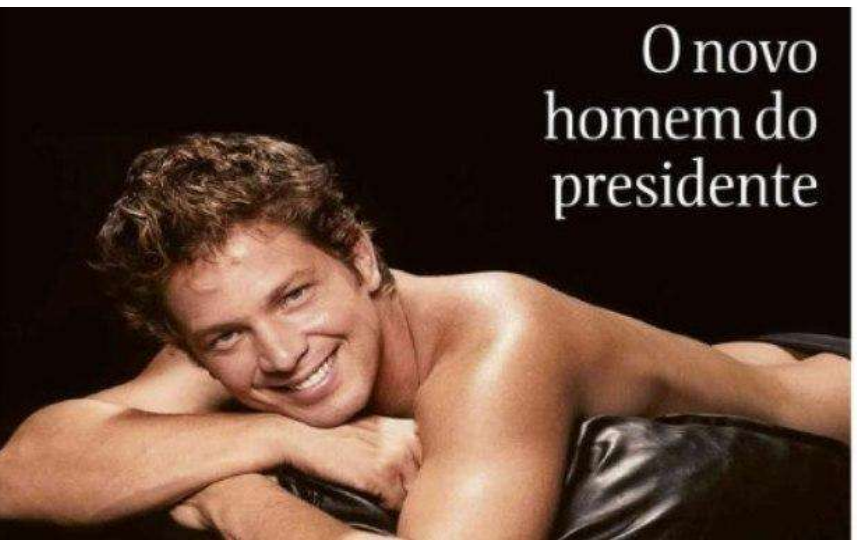

Fonte: <https://www.terra.com.br/diversao/tv/blog-sala-de-tv/foto-com-suposta-pose-gay-usada-para-desmoralizarfrias,e6c6440c1d70f529fdd5b490b5cae50ekc8ogmhh.html>. Acesso em: 08 jul. 2021.

A mesma matéria trabalha com a hipótese de que a pose do nominado secretário da cultura, somada ao título da manchete, aludem ao desvio da heteronorma. Com a chamada explícita "Foto com suposta pose gay é usada para desmoralizar Frias", seu autor argumenta que, em vez da associação ao cargo público, recém-ocupado pelo autor, a crítica é direcionada ao âmbito do privado, caracterizada, aqui, pelo resgate do ensaio realizado há mais de Io anos. É interessante, ainda, reportar ao último parágrafo dessa matéria: "Estamos em 2020 e, inacreditavelmente, homens ainda são induzidos a exibir a (falsa) imagem de macho alpha e achincalhados quando fogem desse estereótipo tóxico atrelado ao conservadorismo" (BENÍCIO, 2020, s./p.).

Sobre a dicotomia de privado e público, cabe destacar a discussão realizada por Brown (20I9), no que tange à tentativa exacerbada de indivíduos neoconservadores, em

\footnotetext{
${ }^{7}$ Não à toa, a mesma matéria traz a informação de que houve respostas de grupos ativistas e militantes LGBTQI+, que protestaram em suas redes sociais contra a maneira como a foto apareceu na matéria principal do caderno "llustrada", da Folha. Uma das manifestações argumentava que tal chamada aludia, ou mesmo justificava, à homofobia, desviando do conteúdo que realmente importava acerca do caso: a inabilidade ou inexperiência do ator na gestão pública da pasta de ministério que lhe fora designada.
} 
expandir a esfera pessoal protegida, a fim de estender a alçada da moralidade tradicional para além dos confins da igreja e da família (BROWN, 2019). Ou seja, nessa lógica, o espaço público da política comum tornou-se uma extensão da moralidade que se deve perscrutar e, de preferência, combater.

Outra matéria, que pode ser encontrada no site de notícias Brasil 247, faz referência à suposta traição da atual primeira-dama, Michelle Bolsonaro, com o ex-ministro da cidadania e atual deputado federal, Osmar Terra. ${ }^{8}$ Também nesse caso houve heterogeneidade de enunciados encontrados nos veículos midiáticos.

Na coluna de opinião da edição de março de 2020 da revista Carta Capital, Valdete Souto Severo (2020, s./p.) deixa bastante explícita sua crítica à inclinação moralista de diversos veículos de comunicação logo no título: "O machismo nosso de cada dia na suposta polêmica de Michelle Bolsonaro: Exploração da vida privada de Michelle Bolsonaro contribui apenas para a disseminação do machismo que já é estrutural em nossa sociedade".

Tais táticas não são necessariamente novas, mas assumem contornos recentes que merecem análises mais apuradas. Safatle (2020) argumenta que na "economia moral", ensejada pelo neoliberalismo triunfante, a sobreposição entre o corpo social de uma nação e a estrutura familiar é utilizada como tática de reiteração da confiança, bem como de manutenção de lógicas patriarcais, características do neoconservadorismo:

\begin{abstract}
Tudo se passa como se a família fosse o modelo de "relações harmoniosas" que teria a força de eliminar o caráter muitas vezes aparentemente intransponível dos conflitos sociais. O familiarismo em política pressupõe a fantasia social da família como núcleo de relações hierárquicas naturalizadas, não problemáticas, da autoridade baseada no amor e na devoção. (SAFATLE, 2020, p. 22).
\end{abstract}

Isso porque "[...] a economia ainda guarda seu traço familiarista" (SAFATLE, 2020, p. 23). As táticas políticas do bolsonarismo reafirmam, a todo o momento, o núcleo familiar como estrutura de governança, seja pela reiterada aparição pública do chefe do Executivo com a primeira-dama; seja com seus filhos. Esse núcleo familiar já fora explorado em diversos contextos políticos autoritários, uma vez que propõe a submissão natural das massas à figura do pater família.

Por questões também levantadas por Biroli (2017) e Brown (2019), Safatle (2020) analisa que a figura da família nuclear guarda lógica originária do oikos que aparece

\footnotetext{
${ }^{8}$ Disponível em: <https://www.brasil247.com/midia/suposto-caso-extraconjugal-de-michelle-bolsonaro-e-osmar-terra-levanome-de-ex-ministro-nos-assuntos-mais-comentados>. Acesso em: I5 ago. 2021.
} 
periodicamente, principalmente quando se acredita que o governo deva fazer o mesmo que uma dona de casa quando falta dinheiro, de modo que essa sobreposição das relações econômicas sociais complexas à lógica elementar da "casa" não visa apenas à produção ideológica de ilusões de naturalidade dos modos de circulação e produção de riquezas. Ela visa à sobreposição fantasmática entre corpo social e o corpo do pai, da mãe e dos irmãos. Sobreposição essa que deve produzir a docilidade em relação à autoridade, a perpetuação de um sentimento de dependência e, principalmente, a naturalização da sujeição de gênero.

Ao escolher um suposto caso de adultério como pauta, é esse ideal de família isenta de contradições e conflitos que a página de notícias visa atacar, não abrindo mão de uma retórica igualmente moralista. Além disso, tal suposição reitera a sexualidade feminina como algo público, no sentido de ser regulado e docilizado quando necessário.

\section{Considerações finais}

O esforço empreendido aqui foi de evidenciar como o conservadorismo moral é uma das principais táticas políticas do governo Bolsonaro, materializando-se em narrativas que deixam sobressair a tônica da moralidade, acionando-a como ferramenta de polarização entre "nós" (os moralistas) e "eles" (os imorais). Assim, a imbricação neoconservadorismo e neoliberalismo é de suma importância na tentativa de analisar o fenômeno do bolsonarismo, pois, para além do rigor com a conduta moral, a figura do "cidadão de bem" também é atinente ao neoliberalismo, uma vez que essa figura identitária diz respeito ao cidadão que tem capital para realizar investimentos e faz parte de um núcleo familiar que pensa a si mesmo por meio da lógica empresarial.

Resgataram-se as discussões que abarcam a diferenciação entre o conservadorismo clássico e o atual para evidenciar as novas nuances e estratégias políticas que tem como finalidade a pavimentação do ideário moral. Nesse emaranhado, a mídia tem papel fundamental na construção de um "inimigo" em comum, "imoral". Isso se evidenciou, como mencionado no decorrer do texto, na construção do antipetismo e na ascensão do bolsonarismo. Esse marco intensifica um descrédito da população perante a mídia tradicional, que passa a ser lida com maior suspeita e dá curso ao antipetismo, já perceptível na retórica da construção do inimigo indesejável para o capital global desde anos anteriores (GALLEGO, 2OI9).

As narrativas analisadas com base nas manchetes de notícias, que dão visibilidade às falas do atual presidente Jair Bolsonaro, demonstram a construção desse inimigo em comum. Cabe ressaltar que suas falas são feitas para serem lidas "não como confrontações políticas a respeito da vida em sociedade, mas como 'ofensas', como 'desrespeito'; suas promessas são permeadas por exortações ao 'cuidado', ao 'amparo'. Como se sabe, 'falas 
constituem seus ouvintes"” (SAFATLE, 2020, p.22). O resultado disso é a produção de um sujeito que sempre reage como ofendido.

Por fim, se evidencia que o conservadorismo moral na agenda das novas direitas resulta em um enfraquecimento da democracia, pois a coloca em xeque, organizando assim uma economia afetiva que mobiliza o ressentimento e o medo nos indivíduos, na tentativa de criar uma identidade coletiva que combate os "imorais", a esquerda etc. "Essa é, portanto, uma interpretação 'despolitizada' da realidade, na medida em que opera o deslocamento para o plano moral daquilo que é produto da ação humana e não da ordem da natureza" (MESSENBERG, 20I9, p. 40). De acordo com a mesma autora, a adoção do moralismo é um campo semântico fértil adotado por esses formadores de opinião e se caracteriza por ideais de cunho claramente conservador.

Por essa razão, é possível afirmar que "as políticas antidemocráticas têm como principal tática uma reafirmação dos pilares da sociedade tradicional: família, religião e nação" (MESSENBERG, 20I9, p. 40), e isso se evidencia na agenda política do bolsonarismo.

\section{Referências}

ALMEIDA, S. L. de A. Neoconservadorismo e liberalismo. In: GALLEGO, E. S. (Org.). Oódio como política: a reinvenção das direitas no Brasil. São Paulo: Boitempo, 20I8. p. 27-32.

BENÍCIO, J. Foto com suposta pose gay usada para desmoralizar Frias: Ex-galã da Globo sofre bullying após ser confirmado como novo secretário especial de Cultura do governo Bolsonaro. Terra, 22 jun. 2020, I6h33. Disponível em: $<$ https://www.terra.com.br/diversao/tv/blog-sala-de-tv/foto-com-suposta-pose-gayusada-para-desmoralizar-frias,e6c6440cid7of529fdd5b490b5cae5oekc8ogmhh.html>. Acesso em: 22 dez. 2020.

BIROLI, F. O rastro da onda: derrocada de direitos e moralismo compensatório. Blog da Boitempo, 20 out. 20I7. Disponível em: $<$ https://blogdaboitempo.com.br/20I7/10/20/orastro-da-onda-derrocada-dos-direitos-e-moralismo-compensatorio/>. Acesso em: 30 mai. 202I.

BIROLI, F.; MACHADO, M. das D. C.; VAGGIONE, J. M. Introdução: matrizes do neoconservadorismo religioso na América Latina. In: BIROLI, F.; MACHADO, M. das D. C.; VAGGIONE, J. M. Gênero, neoconservadorismo e democracia: disputas e retrocessos na América Latina. São Paulo: Boitempo, 2020.

BIROLI, F.; QUINTELA, D. F. Mulheres e direitos humanos sob a ideologia da "defesa da família". In: AVRITZER, L.; KERCHE, F.; MARONA, M. (Orgs.). Governo Bolsonaro: retrocesso democrático e degradação política. Belo Horizonte: Autêntica, 202I. 
BOBBIO, N. Direita e esquerda: razões e significados de uma distinção política. 3. ed. São Paulo: Editora Unesp, 20II.

BROWN, W. Nas ruínas do neoliberalismo: a ascensão da política antidemocrática no ocidente. São Paulo: Editora Filosófica Politeia, 2019.

BURITY, J. A onda conservadora na política brasileira traz o fundamentalismo ao poder? In: ALMEIDA, R. de; TONIOL, R. (Orgs.). Conservadorismos, fascismos e fundamentalismos: análises conjunturais. Campinas: Editora da Unicamp, 2018.

CARVALHO, I. Quilombolas que foram alvo do Bolsonarismo criticam arquivamento de processo de racismo. Brasil de Fato, São Paulo, o7 jun. 2019. Disponível em: $<$ https://www.brasildefato.com.br/2019/o6/o7/quilombolas-que-foram-alvo-debolsonaro-criticam-arquivamento-de-processo-de-racismo $>$. Acesso em: 25 jun. $2 \mathrm{O} 2 \mathrm{I}$.

CARNIEL, F.; RUGGI, L.; RUGGI, J. de O. Género y humor en las redes sociales: la campaña contra Dilma Rousseff en Brasil. Opinião Pública, v. 24, n. 3, p. 523-546, 2018.

CASARA, R. R. R. Bolsonarismo judicial: a tradição autoritária e o modo neoliberal de julgar. In: GALLEGO, E. S. (Org.). Brasil em colapso. São Paulo: Editora Unifesp, 20I9. p. 15-24.

DARDOT, P.; LAVAL, C. A nova razão do mundo: ensaio sobre a sociedade neoliberal. São Paulo: Boitempo, 2016.

DEMIROVIC, A. El populismo autoritario como estrategia de neoliberal de gestión de las crisis. Constelaciones, n. IO, p. II6-I34, 2018.

EM EVENTO do Aliança, Bolsonaro diz que apoiador tem "8 arrobas". Correio Brasiliense, 29 fev. 2020. Disponível em:

$<$ https://www.correiobraziliense.com.br/app/noticia/politica/2020/o2/29/interna_politica ,831254/em-evento-do-alianca-bolsonaro-diz-que-apoiador-tem-8-arrobas.shtml> . Acesso em: 25 jun. 202I.

FREIXO, A. de; PINHEIRO-MACHADO, R. Dias de um futuro (quase) esquecido: um país em transe, a democracia em colapso. In: FREIXO, A. de.; PINHEIRO-MACHADO, R.(Orgs.). In: Brasil em transe: bolsonarismo, nova direita e desdemocratização. Rio de Janeiro: Oficina Raquel, 2019. p. 9-24.

GALETTI, C. Entre afeto e política. Revista Jacobin, 2020.

GALETTI, C.; MELO, J. Discutindo o ressentimento como potencializador da nova direita. Blog da Revista Espaço Acadêmico, 17 mai. 2020. Disponível em: $<$ https://espacoacademico.wordpress.com/2020/05/17/discutindo-o-ressentimentocomo-potencializador-da-nova-direita/>. Acesso em: I5 ago. 202I. 
GALLEGO, E. S. Quem é o inimigo? Retóricas de inimizade nas redes sociais no período 20I420I7. In: Brasil em transe: bolsonarismo, nova direita e desdemocratização. Rio de Janeiro: Oficina Raquel, 2019. p. 83-98.

HARVEY, D. Oneoliberalismo: história e implicações. São Paulo: Loyola, 2013.

JASPER, J. Protesto: uma introdução aos movimentos sociais. Rio de Janeiro: Zahar, 2016.

MESSENBERG, D. A cosmovisão da "nova" direita brasileira. In: FREIXO, A. de.; PINHEIROMACHADO, R.(Orgs.). Brasil em transe: bolsonarismo, nova direita e desdemocratização. Rio de Janeiro: Oficina Raquel, 2019. p. 25-49.

MILL, J. S. Da definição de economia política e do método de investigação próprio a ela. In: BENTHAN, S. M. Os pensadores. São Paulo: Abril Cultural, 1973.

MISKOLCI, R. Estética da existência e pânico moral. In: RAGO, M.; VEIGA-NETO, A.(Orgs.). Figuras de Foucault. 3. ed. Belo Horizonte: Autêntica, 2013.

SAFATLE, V. A economia é a continuação da psicologia por outros meios: sofrimento psíquico e o neoliberalismo como economia moral. In: SAFATLE, V.; JUNIOR, N. da S.; DUNKER, C. (Orgs.). Neoliberalismo como gestão do sofrimento psíquico. Belo Horizonte: Autêntica, 2020.

SCRUTON, R. Oqueé conservadorismo. São Paulo: É Realizações, 2015.

SEVERO, V. S. O machismo nosso de cada dia na suposta polêmica de Michelle Bolsonaro: Exploração da vida privada de Michelle Bolsonaro contribui apenas para a disseminação do machismo que já é estrutural em nossa sociedade. Carta Capital, 15 mar. 2020. Disponível em: $<$ https://www.cartacapital.com.br/opiniao/o-machismo-nosso-de-cada-dia-nasuposta-polemica-de-michelle-bolsonaro/>. Acesso em: 22 dez. 2020.

STANLEY, J. Como funciona of fascismo: a política do "nós" e "eles". 4. ed. Porto Alegre: L\&PM, 2020. 